\title{
Pearlite Stabilisation by Copper on Ductile Cast Iron
}

\author{
Masato Tsujikawa ${ }^{1, a}$, Norikazu Matsumoto ${ }^{2}$, Koji Nakamoto ${ }^{3, b}$, and \\ Yoshisada Michiura ${ }^{3, \mathrm{c}}$ \\ ${ }^{1}$ Department of Materials Science, Osaka Prefecture University, Gakuen-cho1-1, Naka-ku, \\ Sakai-shi, 599-8531 JAPAN \\ ${ }^{2}$ Student, Osaka Prefecture University (present address Sugimoto Co., Ltd.) \\ ${ }^{3}$ Kurimoto, Ltd., Izumi2-1-64, Suminoe-ku, Osaka, 559-0023 JAPAN \\ amasatot@mac.com, ${ }^{b}$ k_nakamoto@kurimoto.co.jp, cy_michiura@kurimoto.co.jp
}

Keywords: spheroidal graphite cast iron, heat treatment, cementite TEM observation

\begin{abstract}
In ductile cast irons with copper, cementite stability was investigated against an annealing heat treatment used to obtain a fully ferritic matrix. Copper controls cast-iron mechanical properties, but its role in the matrix microstructure formation remains unclear. Some reports suggest the copper layer around graphite or cementite. They can be barrier to carbon diffusion at eutectoid reaction, however it is difficult to understand the mechanism of pearlite stability by copper. To confirm the existence of the barrier and effect of copper addtion, ten 9-mm-thick spheroidal graphite cast iron castings were prepared with different copper contents of $0.16 \mathrm{wt} \%-0.69 \mathrm{wt} \%$. The samples' as-cast microstructures included spheroidal graphite, ledeburite, and pearlite. The pearlite fraction degreases to about $10 \%$ by heat treatment for ordinary ductile irons without intentional copper addition. The samples' copper content and the pearlite fraction after heat treatment are not linearly related. The retained pearlite increased suddenly with increased copper content greater than $0.4 \mathrm{wt} \%$. However, even the sample with the highest copper content showed no precipitation of a copper solid solution around graphite nodule or cementite.
\end{abstract}

\section{Introduction}

Cast irons have various microstructures. For example, the matrix structure varies from low-carbon ferrite to high-carbon pearlite or an austempered structure. Spheroidal graphite cast iron with pearlitic matrix is important because of its moderate strength and ductility [1]. Therefore, various methods have been used to make the pearlite structure more stable. Copper has been an effective element for use with cast iron to maintain the matrix pearlite $[2,3]$.

Copper is an interesting element for use in steels and irons [3-6]. Lacaze et al. described in detail the respective roles of copper and manganese for pearlite formation in spheroidal graphite cast irons $[7,8]$. They proposed a mechanism based on the calculated values of austenite decomposition temperature to ferrite graphite system or pearlitic system, in addition to the measured difference in under-cooling required for austenite-ferrite/graphite decomposition and austenite-pearlite decomposition. They reported the respective effects of copper and manganese on microstructure formation.

Many mechanisms have been reported to make pearlite stable. A thin layer of copper solid solution at graphite / matrix interface prevents the decomposition of pearlite [9]. Alternatively, when copper and manganese are added together, the copper in ferrite concentrates the manganese in cementite. Manganese also renders carbide more stable; therefore, the cementite in pearlite is rendered stable [10].

This study investigated the effect of copper addition within $0.7 \mathrm{wt} \% \mathrm{Cu}$ on microstructure formation of spheroidal graphite cast iron during ferritisation annealing. 


\section{Experimental Procedure}

Samples were centrifugally cast into 9-mm-thick pipes using one melt from a cupola. Changing the copper in the ladle varied the copper contents of the respective samples. Chemical compositions of the samples are presented in Table 1. Ten samples with different copper contents were obtained. The copper contents were, respectively, $0.164 \mathrm{wt} \%, 0.189,0.241,0.317,0.386,0.432,0.486,0.553,0.657$, and 0.692. Microstructures of the as-cast materials were as presented in Fig. 1. They consisted of spheroidal graphite, ledeburite, and pearlite, irrespective of copper content. As-cast samples were annealed at $1250 \mathrm{~K}$ for $15 \mathrm{~min}$ and cooled to $1050 \mathrm{~K}$ with cooling speed of $25 \mathrm{~K} / \mathrm{min}$, then cooled to $910 \mathrm{~K}$ with $5 \mathrm{~K} / \mathrm{min}$. Subsequently, they were air-cooled to room temperature. The matrix of ordinary ductile cast irons without copper addition became fully ferritic by this heat treatment.

Table 1 Chemical compositions of samples

\begin{tabular}{ccccccccc}
\hline \hline $\mathrm{C}$ & $\mathrm{Si}$ & $\mathrm{P}$ & $\mathrm{S}$ & $\mathrm{Mn}$ & $\mathrm{Mg}$ & $\mathrm{Cr}$ & $\mathrm{Sn}$ & $\mathrm{Cu}$ \\
\hline 3.66 & 1.73 & 0.047 & 0.002 & 0.25 & 0.035 & 0.08 & 0.009 & $0.164-0.692$ \\
\hline
\end{tabular}

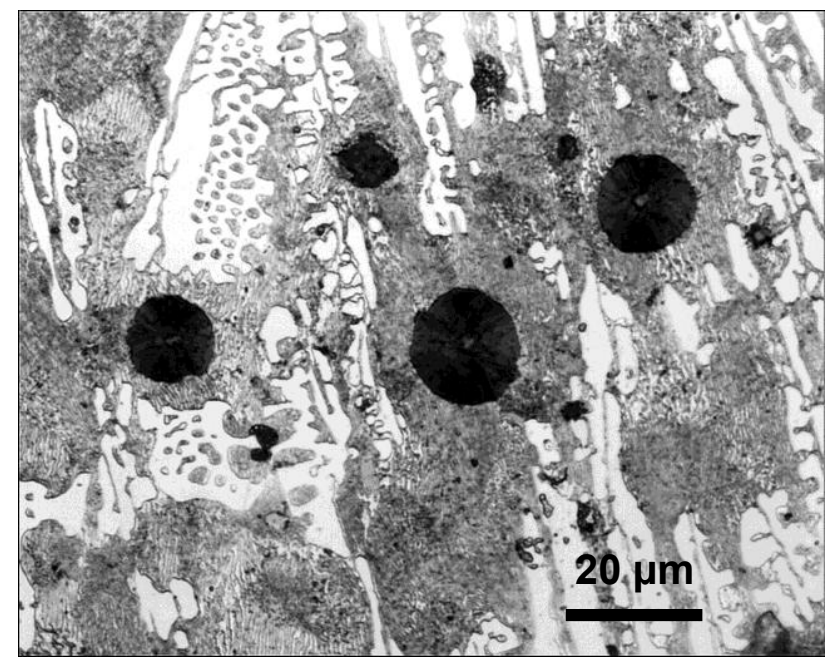

....

Fig. 1 Example of as-cast sample, $0.16 \mathrm{wt} \% \mathrm{Cu}$ alloy.

The hardness and tensile properties of the samples were measured. The tensile specimens were cut longitudinally from the pipes after annealing, and were $20-\mathrm{mm}$ long with a $6-\mathrm{mm}$ diameter parallel body for gauging. The microstructures were observed in detail using transmission electron microscopy (TEM). The TEM samples were made using focused ion beam ablation technique (FIB). We observed a graphite/matrix interface in the pearlite and ferrite/ cementite interface.

\section{Results and Discussion}

Relation between Copper Content and Pearlite Volume Fraction. The effect of copper addition on pearlite stability is shown in the microstructures presented in Fig. 2. The fraction of pearlite in the matrix becomes greater with increasing copper content. Fig. 3 shows the relation between copper content and pearlite volume fraction with values from literatures $[2,8]$ measured for different manganese content. The volume fraction of graphite nodules is not counted.

When the copper content was greater than about $0.4 \mathrm{wt} \%$, the pearlite volume fraction increased significantly on $0.25 \mathrm{wt} \% \mathrm{Mn}$ series, as depicted in Fig. 2 . The pearlite fractions differ greatly among them, although the difference in copper content is smaller than $0.07 \%$. Such abrupt increase in pearlite volume fraction was occurred around $0.6 \mathrm{wt} \% \mathrm{Cu}$ for the specimen series with smaller manganese content [8]. 
Mechanical Properties. The influence of copper content on mechanical properties is portrayed in Fig. 4. Brinell hardness and strength of the ductile irons are increased concomitantly with increasing copper content.

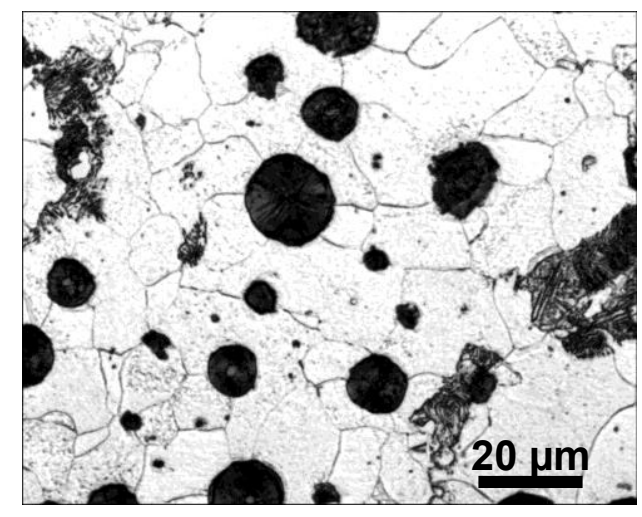

(a) $0.16 \mathrm{wt} \% \mathrm{Cu}$

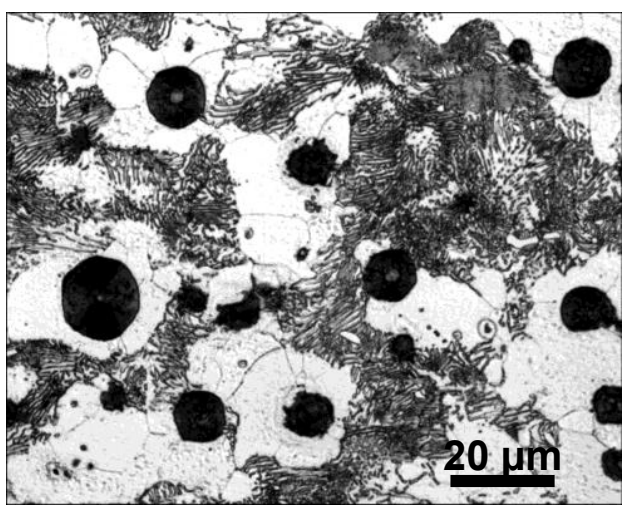

(c) $0.39 \mathrm{wt} \% \mathrm{Cu}$

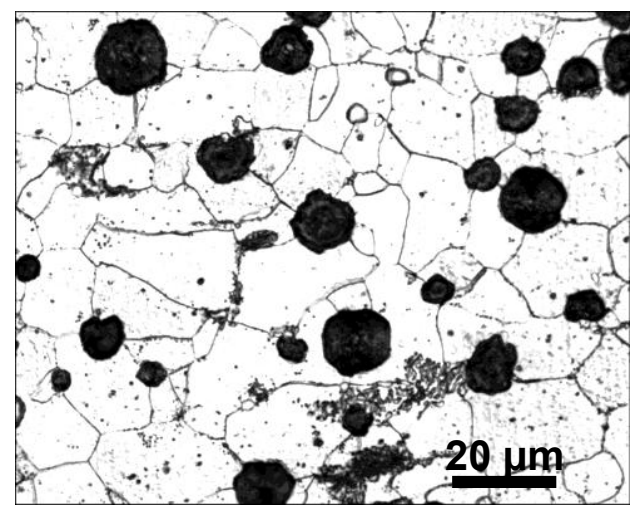

(b) $0.32 \mathrm{wt}^{\mathrm{O}} \% \mathrm{Cu}$

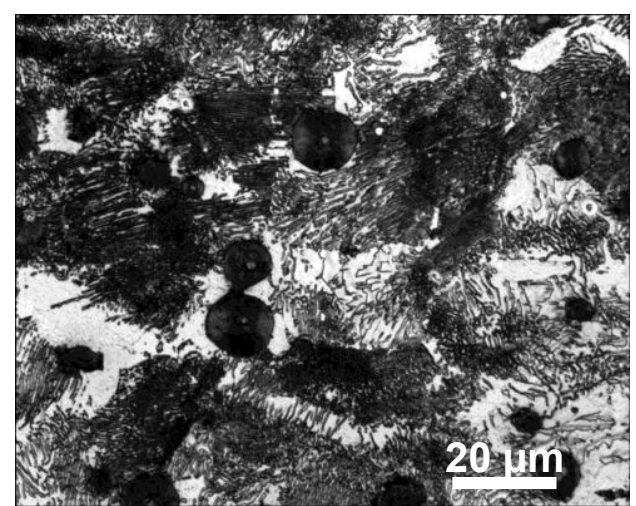

(d) $0.69 \mathrm{wt} \% \mathrm{Cu}$

Fig. 2 Microstructures of annealed samples.

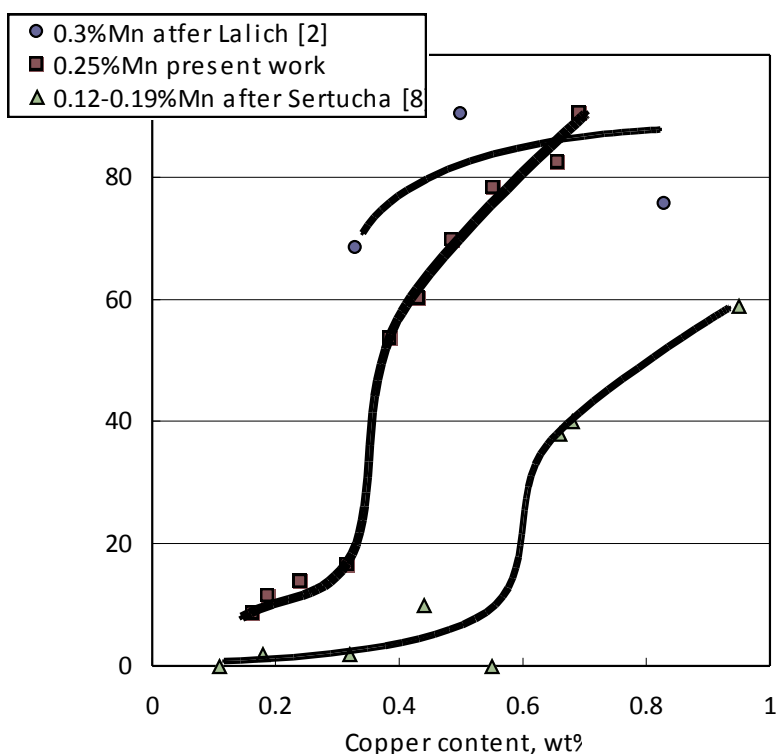

Fig. 3 Effect of copper addition on pearlite fraction in matrix.

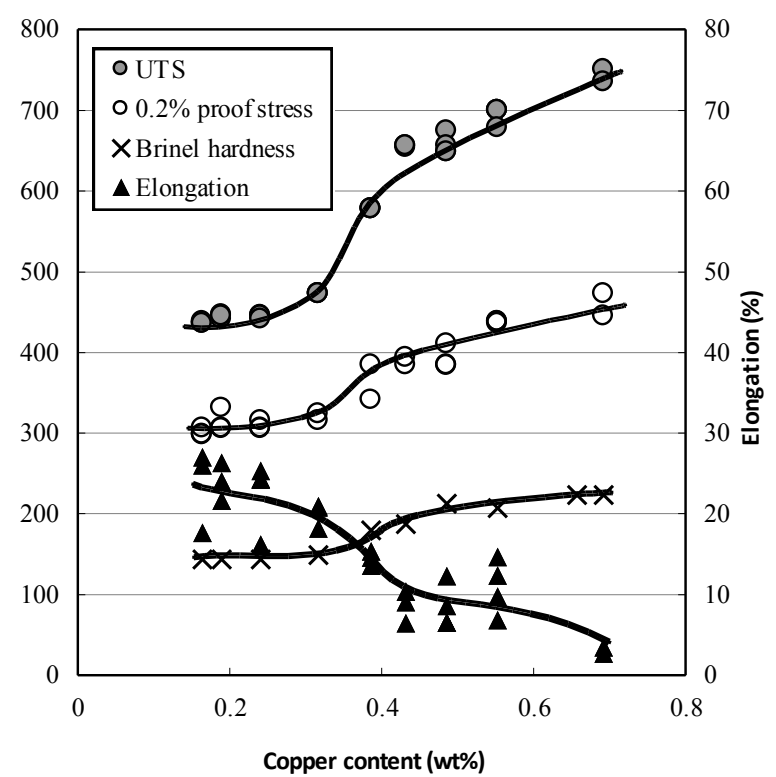

Fig. 4 Hardness and result of tensile tests, $0.25 \mathrm{wt} \% \mathrm{Mn}$. 
The behaviour of the strength increases with copper content, just as the pearlite fraction increases with copper content, as depicted in Fig. 3. Actually, the tensile strength and $0.2 \%$ proof stress are proportional to the pearlite volume fraction. The ductility shows an opposite relation to that of strength. These results are comparable with those obtained for ordinary ductile cast iron with different pearlite volume fractions without copper addition [11].

Phase Diagram. Some Some differences might exist in microstructure formation at about $0.4 \% \mathrm{Cu}$. It is important to confirm the stable phases using the phase diagram. However, experimental phase diagram information for ternary or higher-order alloy systems is rare and often absent. Therefore, using thermodynamic equilibrium calculations to facilitate design and optimisation of the compositions and processing parameters of a multi-component alloy would be an advanced and acceptable approach. Computational thermochemistry, as used in the calculation of phase diagrams (CALPHAD) approach, can provide a clear image for such systems as $\mathrm{Fe}-\mathrm{C}-\mathrm{Si}-\mathrm{Cu}$ alloy.

Thermo-Calc (Termo-Calc Sofrware AB) thermodynamic software was used. Fig. 5(a) shows an $\mathrm{Fe}-\mathrm{Cu}$ phase diagram that is fixed $3.66 \mathrm{wt} \% \mathrm{C}$ and $1.73 \mathrm{wt} \% \mathrm{Si}$. These values are comparable to those of samples in this study. Similarly, a calculated Fe-C phase diagram is shown in Fig. 5(b) for copper content fixed at $0.7 \mathrm{wt} \%$ and silicon content fixed at $1.73 \mathrm{wt} \%$. The copper dissolves completely in ferrite and austenite in the copper content range of this study. It is clear that the solid solution phase of copper, $\varepsilon$ phase, should not precipitate.
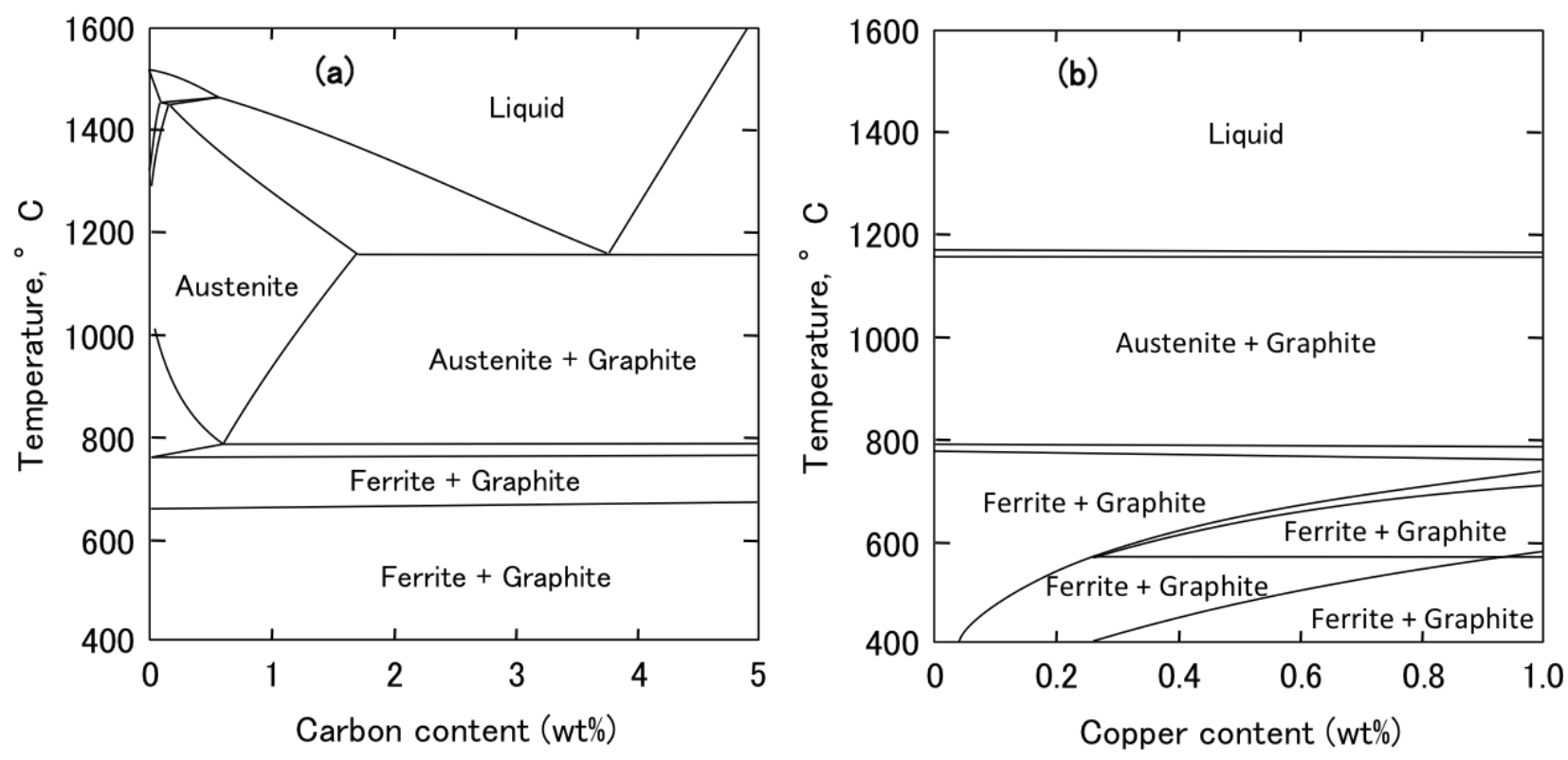

Fig. 5 Calculated Fe-C-Si-Cu quaternary phase.

(a) $1.73 \mathrm{wt} \% \mathrm{Si}-0.7 \mathrm{wt} \% \mathrm{Cu}$ section, (b) $3.66 \mathrm{wt} \% \mathrm{C}-1.73 \mathrm{wt} \% \mathrm{Si}$ section.

TEM Observations. The microstructure of the $0.692 \mathrm{wt} \% \mathrm{Cu}$ sample was observed using TEM. Fig. 6(a) shows the whole specimen prepared using FIB. Although some separation is apparent at the interface between graphite and matrix, no evidence of copper phase exists, as shown in (b) and (c). Figs. 6(d) and 6(e) are areas of pearlite. No evidence of copper phase is visible. For example, the selected area electron beam diffraction analysis (SAD) for site (e) shows only diffraction patterns for ferrite and cementite. 


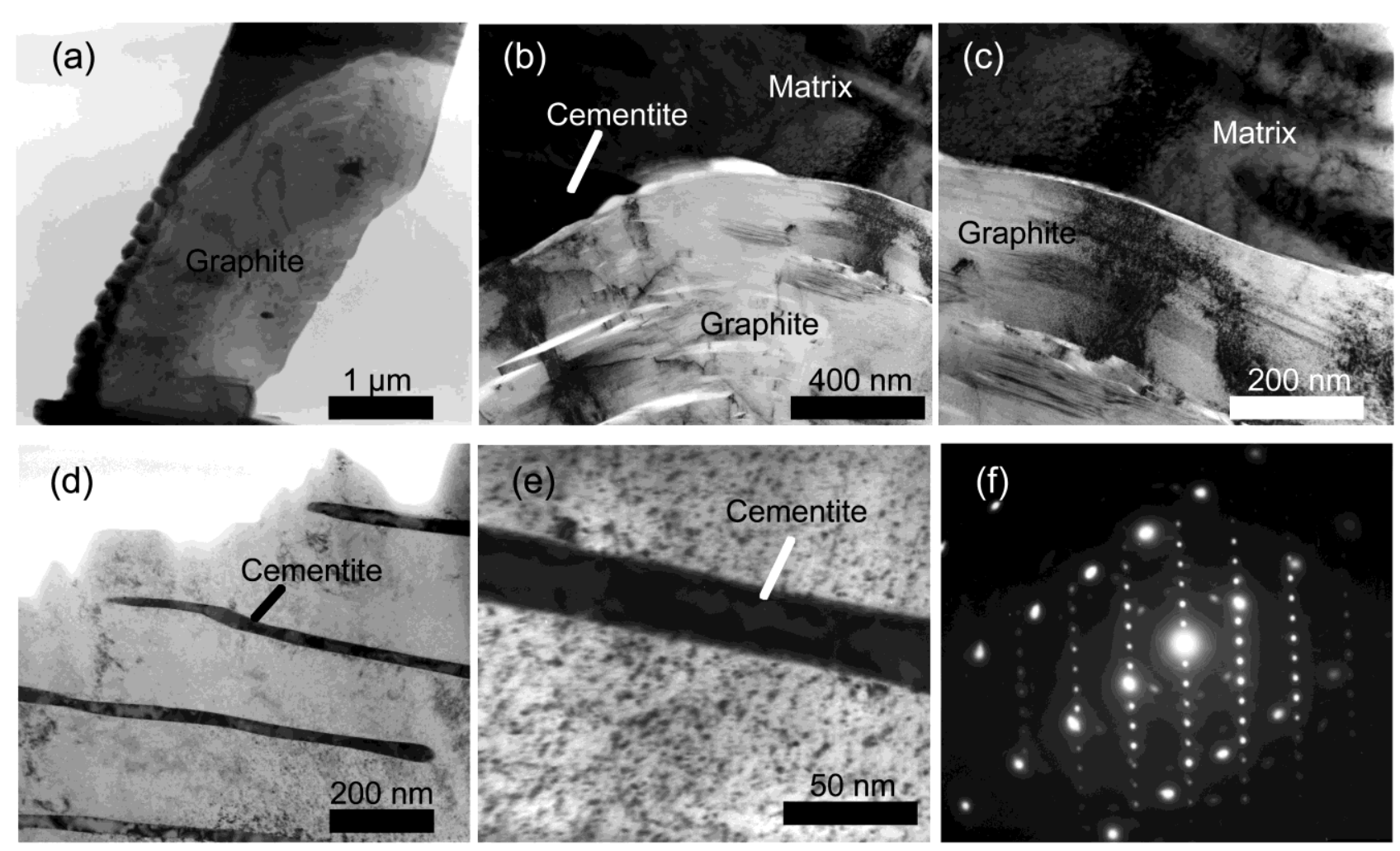

Fig. 6 Microstructures of graphite/matrix and cementite/matrix interfaces.

(a) Thinned sample by FIB, (b)(c) graphite/matrix interface, (d) pearlite,

(e) ferrite/cementite interface in pearlite, and SAD of area (e).

Fig. 7 shows the micro-Vickers hardness of the ferritic part or pearlitic part of the samples. The value of $\mathrm{Cu}$ free in the figure was measured for a ferritisation annealed spheroidal graphite cast iron cast as 1-inch thick keelblock. Measured values are scattered because of the subsurface uncertainty. In the region around $0.3 \mathrm{wt} \% \mathrm{Cu}$, the values are unreliable because the ferritic matrix and pearlitic matrix are complexly mixed together. Nevertheless, the average values of samples indicate that the hardness of ferrite phase is increasing with copper content by solution hardening, and that the hardness of pearlite is affected only slightly by copper contents.

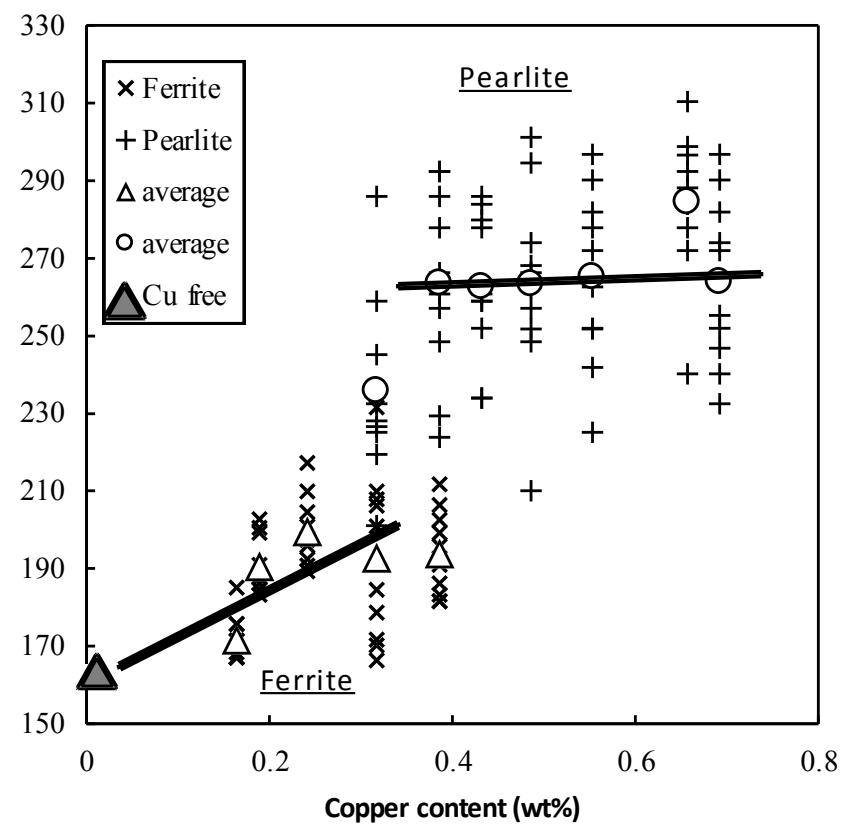

Fig. 7 Matrix constituent hardness in relation to the sample copper content. 
As suggested by the phase diagrams shown in Fig. 5, copper dissolves in austenite. After cooling to just below the eutectoid reaction, copper also can dissolve in ferrite in the copper content range used for this study. That is, the copper content of the ferrite phase in the pearlite increased with additional copper content. In the $\gamma$-Fe phase, copper with ion diameter greater than iron expands the lattice. Copper has no great affinity to carbon: it hastens the diffusion of carbon [12]. Then the decomposition of austenite with higher copper content proceeds faster than that of lower copper content, which is convenient for ferrite-graphite decomposition of the meta-stable eutectoid product, pearlite. The presence of manganese, as reported by Lacaze [7], has the important role of stabilising cementite. Kawano et al. reported that the higher concentration of copper in austenite promotes higher concentration of manganese in cementite in pearlite [10]. It might be true that the origin of pearlite stability by copper addition is the manganese concentration into cementite by copper. The manganese concentration in cementite sufficient to stabilise the cementite activated copper content is greater than $0.4 \mathrm{wt} \%$; in this study, manganese contents were $0.35 \mathrm{wt} \%$.

\section{Conclusions}

(1) In ductile cast iron with $0.25 \mathrm{wt} \% \mathrm{Mn}$ after ferritisation annealing, the pearlite volume fraction increased considerably when copper contents were greater than $0.4 \mathrm{wt} \%$. The critical value of copper for pearlite fraction move to higher content with decreaseing manganese content.

(2) Mechanical properties depended on the pearlite volume fraction when copper contents were less than $0.7 \mathrm{wt} \%$.

(3) In terms of the solid solubility limit, copper can dissolve into iron at least $1.0 \mathrm{wt} \%$. Copper phase should not appear for copper contents used in this study. That was confirmed using TEM observation, which revealed no copper phase in the ferrite-cementite interface or the graphite-matrix interface.

\section{References}

[1] G. S. Cho, K. H. Choe, K. W. Lee and A. Ikenaga: Journal of Materials Science and Technology Vol. 23 (2007), p. 97

[2] M. J. Lalich and C. R. Loper Jr: Trans Am Foundrymen's Soc Vol. 81 (1974), p. 217

[3] M. T. Miglin, J. P. Hirth, A. R. Rosenfield and W. A. T. Clark: Metallurgical transactions. A, Vol. 17 (1986), p. 791

[4] J. A. Sikora, H. A. Dall'O, R. E. Boeri and H. R. Ortiz: Foundryman Vol. 79 (1986), p. 180

[5] M. Mujahid, A. K. Lis, C. I. Garcia and A. J. DeArdo: Proceedings of the International Conference on Processing, Microstructure and Properties of Microalloyed and Other Modern High Strength Low Alloy Steels, (1992), p. 345

[6] K. Osamura, H. Okuda, S. Ochiai, M. Takashima, K. Asano, M. Furusaka, K. Kishida and F. Kurosawa: ISIJ International Vol. 34 (1994), p.359

[7] J. Lacaze, A. Boudot, V. Gerval, D. Oquab and H. Santos: Metallurgical and Materials Transactions AVol. 28 (1997), p.2015

[8] J. Sertucha, P. Larrañaga, J. Lacaze and M. Insausti: International Journal of Metalcasting Winter 10 (2010), p.51

[9] G. I. Sil'man, V. V. Kamynin and A. A. Tarasov: Metal Science and Heat Treatment Vol. 45 (2003), p.254

[10] Y. Kawano, S. Yamamoto, K. Kawase and N. Inoyama: Imono Vol. 62 (1990), p.510

[11] M. Hafiz: Journal of Materials Science Vol. 36 (2001), p.1293

[12] M. Tsujikawa, M. Egawa, N. Ueda, A. Okamoto, T. Sone and K. Nakata: Surface \& Coatings Technology Vol. 202 (2008), p.5488 